
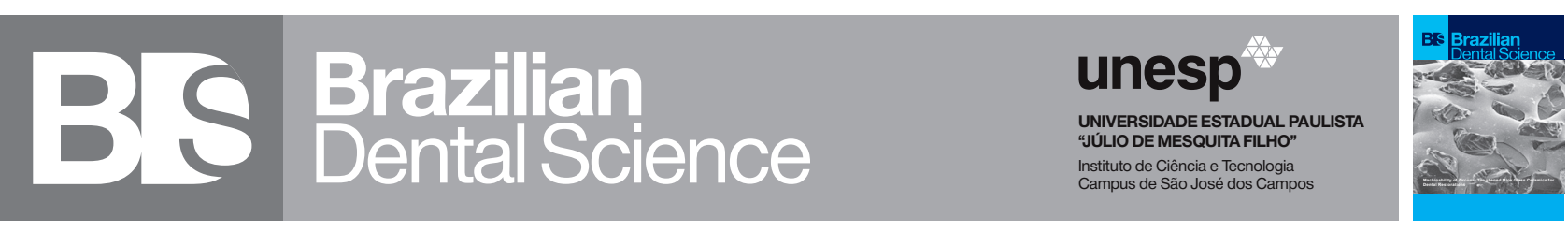

\title{
Sex determination by osteometric assessment of the mastoid process using Cone Beam Computed Tomography
}

Determinação do sexo em uma população Iraniana por avaliação osteométrica do processo mastóide em imagens de TCFC

Fatemeh SALEMI ${ }^{1}$, Maryam FARHADIAN ${ }^{2}$, Abbas SHOKRI ${ }^{1}$, Yaser SAFI ${ }^{3}$, Shahin RAHIMPANAH ${ }^{4}$

1 - Department of Oral and Maxillofacial Radiology, School of Dentistry, Hamadan University of Medical Sciences, Hamadan, Iran.

2 - Department of Biostatistics, School of Public Health and Research Center for Health Sciences, Hamadan University of Medical Sciences, Hamadan, Iran.

3 - Department of Oral and Maxillofacial Radiology, School of Dentistry, Shahid Beheshti University of Medical Sciences, Tehran, Iran.

4 - School of Dentistry, Hamadan University of Medical Sciences, Hamadan, Iran.

\section{ABSTRACT}

Objective: Sex determination is one of the most important parameters to identify in forensic science. Because the mastoid process is the most resistant to damage due to its position in the skull base, it can be used for sex determination. The purpose of this study was to measure the dimensions and convexity and internal angles of the mastoid process to present a model of sex determination in Iranian population. Material and methods: This study was performed on three-dimensional images of 190 Cone Beam Computed Tomography (CBCT) of 105 women and 85 men. On each CBCT the distance between the porion and the mastoid (PM), mastoid length (ML), the distance between the mastoidale and the mastoid incision (M-I), the mastoid height $(\mathrm{MH})$, the mastoid width (MW), intermastoidale distance (IMD) the lateral surfaces of the left and right mastoids (IMLSD) and the Mastoid medial convergence angle (MMCA) was measured on both the right and the left. The data were analyzed by descriptive statistics, t-test, and discriminant function analysis. Results: Significant differences were found for all variables except MMCA and MF in both sex. All measured variables except MW were greater for men than women. The discriminant model achieved a total accuracy of $93.7 \%$. Among the measured factors IMD and IMSLD had the most influence on sex determination. Conclusion: Measuring the dimensions of the mastoid process is a very good method for sex determination with high accuracy of $90 \%$.

\section{KEYWORDS}

Discriminant model; Cone beam computed tomography (CBCT); Sex determination; Mastoid process.

\section{RESUMO}

Objetivo: A determinação do sexo é um dos parâmetros mais importantes para identificação na ciência forense. Por ser o processo mastóide resistente a danos, devido a sua posição na base do crânio, este poderia ser usado na determinação do sexo. O objetivo deste estudo foi mensurar as dimensões, convexidade e ângulos internos do processo mastóide para apresentar um modelo de determinação do sexo em uma população Iraniana. Material e métodos: Este estudo foi realizado em 190 imagens de tomografia computadorizada de feixe cônico (TCFC), sendo 105 mulheres e 85 homens. Em cada TCFC foram realizadas medidas no processo mastóide em comprimento (ML), altura (MH), largura (MW) em ambos os lados direito e esquerdo, também foi medida a distância entre o Pórion e o processo mastóide (PM), distância até incisura mastoidea (M-I), distância entre as superfícies mediais (IMD) distância entre as superfícies laterais dos processos direito e esquerdo (IMLSD) e o ângulo de convergência medial (MMCA). Os dados foram analisados por estatística descritiva, teste $\mathrm{t} e$ análise de função discriminante. Resultados: Diferenças significativas foram encontradas para todas as variáveis, exceto MMCA e MF em ambos os sexos. Todas as variáveis medidas, exceto MW, foram maiores para os homens do que para as mulheres. $\mathrm{O}$ modelo de análise de função discriminante alcançou uma precisão total de 93,7\%. Entre os fatores medidos, o IMD e o IMSLD tiveram a maior influência na determinação do sexo. Conclusão: Podemos concluir que as dimensões do processo mastóide constituem um método para determinação do sexo, em população Iraniana, com precisão de $90 \%$.

\section{PALAVRAS-CHAVE}

Análise para determinação do sexo; Modelo discriminativo; Processo mastoide; Tomografia computadorizada de feixe cônico. 


\section{INTRODUCTION}

I dentifying the sex of victims in wars and accidents is one of the most difficult tasks. Severe burns, hair loss and severe breakdown of the body make it difficult and even impossible to determine sex [1]. Identifying isolated human remains in major disasters and when a dead person's body is amputated or decomposed into multiple parts is one of the critical parts in forensics [2]. In such cases, the main focus is on establishing a person's biological profile by estimating age, sex, and race and estimating sex is one of the important parameters in establishing biological profiles of unknown remains. Estimation of sex is based on the sexual dimorphism present in the body [3]. The human skeleton contains calcified hard tissue that can sustain severe condition and if all the bones that make up the skeleton are present, it's not difficult to estimate sex. However in explosions, plane crashes, and natural disasters that the body is divided into several parts, it is necessary to find a suitable method for sex determination of residual bone fragments [4].

Much research has been done to estimate sex, some of which have been done on the long bones [5], skulls [6] and pelvis [7]. According to a study by Jscan and krogman [8], pelvis and skull are common sexed markers and the morphological evaluation and size and shape of these bones is most accurate in estimating sex. If the pelvis is present with $95 \%$ accuracy, sex can be identified but when the pelvis is unavailable, the skull is also widely recognized as the best sex marker. After the pelvis, the skull has the most sex dimorphism and is more than $92 \%$ reliable in estimating sex [4].

There are two basic methods for sex determination of human skull bones: morphological and morphometric methods. The morphological method is based on the observation of the sex dual features of the skull and the morphometric approach is to estimate sex using specific skull measurements such as linear, relative and angular measurements. The
Morphometric method is of higher value than the morphological method [9]. Sex estimation studies have been performed on isolated areas of the skull such as teeth [10], nasal bones [11], frontal bones [12], occipital bone [13] and foramen magnum [14].

The mastoid triangle is a part of the temporal bone that has slow and delayed growth and, on the other hand, is highly resistant to physical injury. The mastoid process is desirable for sex determination for two reasons: One is that the compressed structure of the Petros section and its conserved position at the base of the skull make the mastoid to remain even if the skull is fragmented. Second, mastoid is an area that exhibits high degrees of difference between males and females in adulthood $[15,16]$.

Dimorphic variation occur during intrauterine life and afterwards, in the size, length and weight of bones and certain factors such as growth pattern and muscle attachment to the bones also play a significant role in the dimorphic features.[1] Men grow stronger and longer than women and this pattern of prolonged growth causes differences in the size of the bones, especially the skull bones [17]. The mastoid process is one of the dual sex markers so that women have smaller mastoid size than men [18]. The mastoid region is considered one of the slowest and most recent areas of cranium growth and the growth of the mastoid process in response to the activity of the muscles attached to it results in the further development of the mastoid process in men [16]. Most previous studies have been conducted to determine sex using a mastoid triangle and have used direct measurements on dry human skulls or measurements on two-dimensional xerographic copies of the mastoid region [19]. However, in the present study, 3D images from Cone Beam Computed Tomography (CBCT) were used for linear and angular measurement of the mastoid region. CBCT provides high-resolution images and low radiation dose to CT of the maxillofacial region and makes it possible to produce 3D images 
of the skull bones. Recognition using imaging is efficient and relatively easy and can be used in living and dead people and it can be an auxiliary tool in identifying individuals and solving forensic problems [20]. Sexual dimorphism can be achieved by analyzing the discriminant model, which is a statistically objective method of sex determination. Discriminant model analysis can identify the parameters that have the most effect on sex differentiation [21]. The purpose of this study was to present a discriminant analysis model for sex determination in the Iranian population by measuring dimensions and convexity and internal angle of mastoid triangle in CBCT images.

\section{MATERIAL AND METHOD}

In this retrospective study with a specific ethical identity (IR.UMSHA.REC.1397.715), 190 CBCT belonging to patients referred to Oral, Maxillofacial Radiology Department of Hamadan Dental School ranged in age from 18 to 70 years was studied. Exclusion criteria included images with severe artifacts and images that did not show anatomical details of the mastoid and patients with a maxillofacial anomaly. Inclusion criteria containing all CBCTs designed for implant replacement and other therapeutic purposes. All reviewed CBCTs were provided by NewTom 3G (NewTom, Verona, Italy) with 110 kvp conditions, $3.87 \mathrm{~mA}$ tube current, $3.6 \mathrm{~mA}$ Exposure Time, and $180 \mu \mathrm{m}$ voxel size and FOV $=12$ inches and stored in NNT software. First, the CBCT images were converted to DICOM format and transferred to OnDemand software (cybermed seoul, Korea) and by the 3D part of the software, a 3D image was created.

Five anatomical landmarks are then identified on the right and left mastoid:

1. Porion (upper the external discriminantory meatus);

2. Incisura mastoidea (mastoid incision lies on the inferior-medial mastoid);

3. Mastoidale (The lowest point of the mastoid triangle);
4. The most prominent point on the lateral surface of the convex mastoid triangle;

5. The highest point at the mastoid surface (within the digastric cavity).

Accordingly, nine linear measurements were made by software linear measurement tool and one angular measurement by software angular measurement tool on a 3D image as follows:

(PM): The linear distance between the porion and the mastoidale in lateral view

(IM): The distance between the mastoid incision and mastoidale in lateral view

Mastoidale Length (ML): The distance between the porion and the mastoid incision in lateral view

Mastoidale Height (MH): The perpendicular line of the mastoidale on the line between the porion and the mastoid incision in lateral view

Mastoidale Width (MW): The distance between the most prominent point on the lateral surface of the convex mastoid triangle and the highest point on the inner surface of the mastoid triangle (within the digastric cavity) in the inferior view.

Mastoidale flare (MF): The distance between the lowest point of the mastoid triangle and the most prominent convex surface of the mastoid in the posterior view.

Intermastoidale Distance (IMD): The distance between the lowest point of the right and left mastoid triangles in the posterior view.

Intermastoidale Lateral Surface Distance (IMLSD): The distance between the most prominent convex surface points of the right and left mastoid triangles in the posterior view.

Mastoidale Medial Convergence Angle (MMCA): The angle between two lines drawing from the most prominent right and left mastoid points in the posterior view (Figures 1-3). 


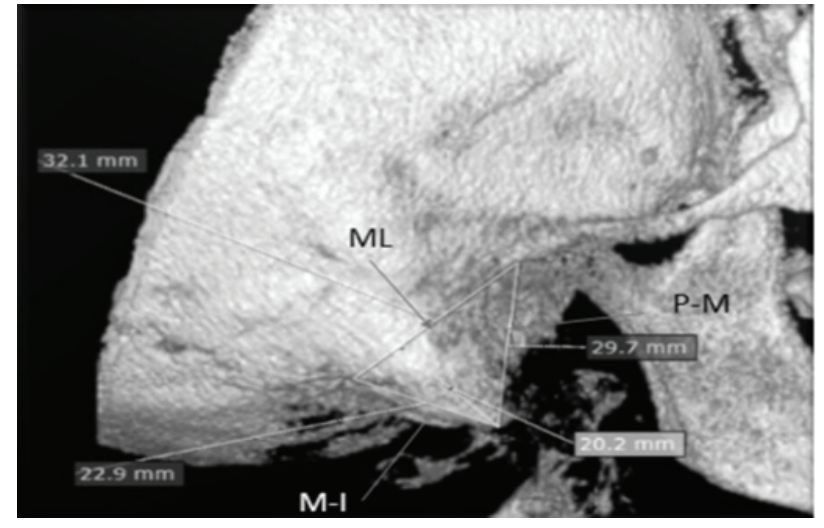

Figure 1 - Mastoid length (ML), mastoid height $(\mathrm{MH})$, the distance between the porion and the mastoid (PM) and the distance between the mastoidale and the mastoid incision (MI) measurements.

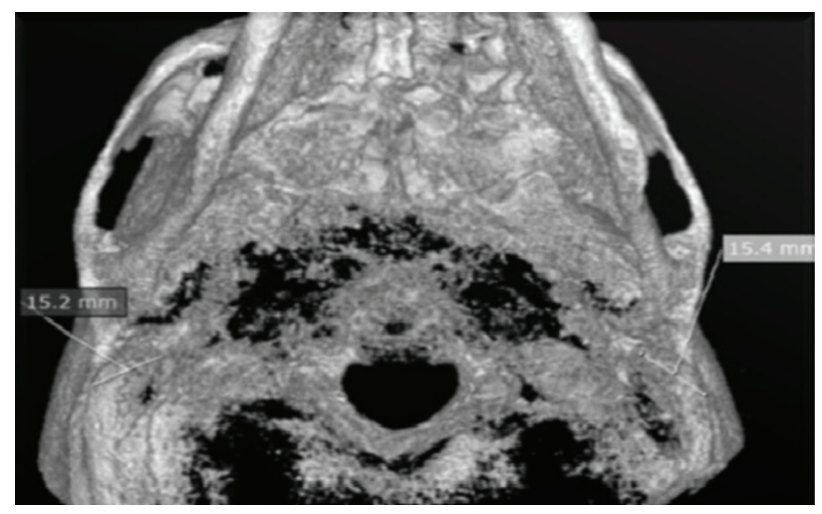

Figure 2 - The mastoid width is indicated on the left and right sides.

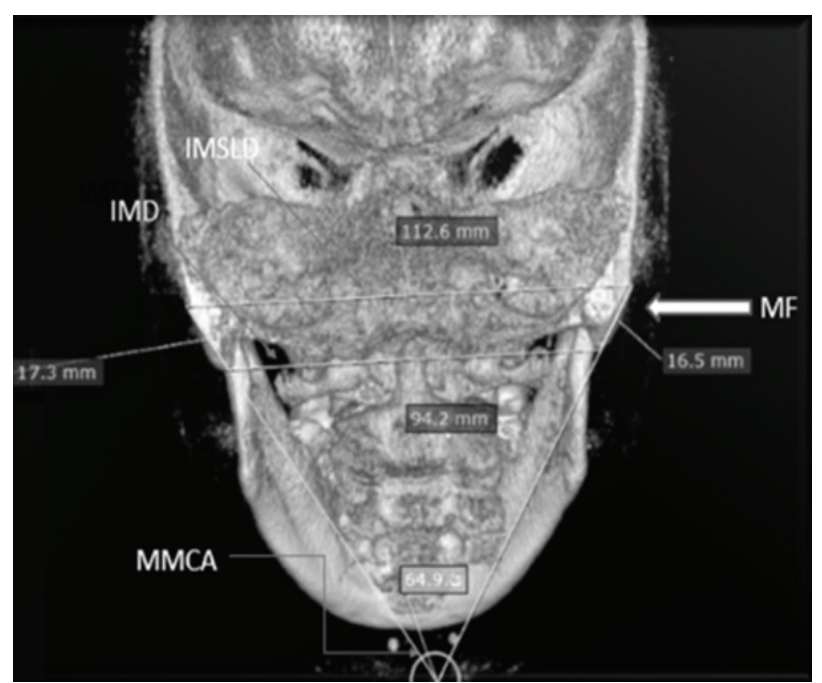

Figure 3 - MF, IMD, IMSLD and MMCA measurements.
All measurements were performed by two observers and twice within two weeks (to measure interobserver and intraobserver agreement. The specified values were inserted into the checklist prepared for this purpose. Statistical analysis was performed by SPSS 21 software. Data were analyzed using descriptive statistics and statistical tests such as t-test and discriminant analysis. Significance level was considered 0.05 .

\section{RESULTS}

Descriptive statistics (mean and standard deviation) and paired t-test, independent t-test, and linear discriminant analysis were used to analyze the data. Significance level was considered $\mathrm{a}=0.05$ in all tests and P-value $<$ 0.05 was considered statistically significant. The results of calculating the intra-class coefficient for measuring internal agreement ( $\mathrm{IC}_{\text {Cobserver1 }}$ $=0.935)$ and $\left(\mathrm{IC}_{\text {Cobserver } 2}=0.955\right)$ as well as, agreement between two observers (ICC ${ }_{\text {Two observer }}$ $=0.907)$, showed that two observers have a high internal and external agreement. Of the 190 samples studied, 105 (55.3\%) were female and $85(44.7 \%)$ were male. The mean age in females was $34.51 \pm 15.33$ and in males 34.91 \pm 13.12 . The age difference between the two sexes was not significant. T-test was used to compare the variables studied in both sexes. The results are presented in Table 1. According to Table 1, except for MF.R, MF.L, and MMCA, significant differences were observed in the mean of all variables between the two sexes. In all variables except MW.R and MW.L, the measured values were higher for men than women. Paired t-test for comparison of right and left side measurements showed no significant difference between measured variables of the mastoid triangle on right and left and therefore the discriminant analysis model was built on the right side variables. 
Table 1 - Comparison of variables in both sexes.

\begin{tabular}{|c|c|c|c|c|}
\hline Variable & Sex & Mean \pm SD & Mean difference \pm SE & P-value \\
\hline P-M.R ${ }^{1}$ & $\begin{array}{l}\text { Female } \\
\text { Male }\end{array}$ & $\begin{array}{l}28.36 \pm 3.16 \\
33.30 \pm 3.20\end{array}$ & $-4.943 \pm 0.464$ & $<0.001$ \\
\hline P-M.L² & $\begin{array}{l}\text { Female } \\
\text { Male }\end{array}$ & $\begin{array}{r}28.63 \pm 3.11 \\
32.99 \pm 3.25\end{array}$ & $-4.356 \pm 0.464$ & $<0.001$ \\
\hline ML.R ${ }^{3}$ & $\begin{array}{l}\text { Female } \\
\text { Male }\end{array}$ & $\begin{array}{c}32.93 \pm 2.80 \\
36.33 \pm 3.12\end{array}$ & $-3.405 \pm 0.430$ & $<0.001$ \\
\hline ML.L ${ }^{4}$ & $\begin{array}{l}\text { Female } \\
\text { Male }\end{array}$ & $\begin{array}{l}33.08 \pm 3.04 \\
36.29 \pm 2.97\end{array}$ & $-3.207 \pm 0.439$ & $<0.001$ \\
\hline MI.R ${ }^{5}$ & $\begin{array}{l}\text { Female } \\
\text { Male }\end{array}$ & $\begin{array}{c}20.13 \pm 3.15 \\
24.19 \pm 3.69\end{array}$ & $-4.067 \pm 0.497$ & $<0.001$ \\
\hline MI.L ${ }^{6}$ & $\begin{array}{l}\text { Female } \\
\text { Male }\end{array}$ & $\begin{array}{l}20.01 \pm 2.99 \\
23.56 \pm 2.45\end{array}$ & $-3.548 \pm 0.439$ & $<0.001$ \\
\hline MH. $\mathrm{R}^{7}$ & $\begin{array}{l}\text { Female } \\
\text { Male }\end{array}$ & $\begin{array}{r}16.91 \pm 2.63 \\
23.56 \pm 2.45\end{array}$ & $-4.419 \pm 0.390$ & $<0.001$ \\
\hline MH.L ${ }^{8}$ & $\begin{array}{l}\text { Female } \\
\text { Male }\end{array}$ & $\begin{array}{l}16.66 \pm 2.452 \\
20.66 \pm 2.450\end{array}$ & $-4.008 \pm 0.357$ & $<0.001$ \\
\hline MW.R ${ }^{9}$ & $\begin{array}{l}\text { Female } \\
\text { Male }\end{array}$ & $\begin{array}{l}19.01 \pm 2.26 \\
17.56 \pm 1.99\end{array}$ & $1.452 \pm 0.313$ & $<0.001$ \\
\hline MW.L ${ }^{10}$ & $\begin{array}{l}\text { Female } \\
\text { Male }\end{array}$ & $\begin{array}{l}19.45 \pm 2.53 \\
17.82 \pm 2.09\end{array}$ & $1.630 \pm 0.342$ & $<0.001$ \\
\hline MF.R ${ }^{11}$ & $\begin{array}{l}\text { Female } \\
\text { Male }\end{array}$ & $\begin{array}{l}17.33 \pm 2.45 \\
17.53 \pm 2.88\end{array}$ & $-0.204 \pm 0.387$ & 0.599 \\
\hline MF.L ${ }^{12}$ & $\begin{array}{c}\text { Female } \\
\text { Male }\end{array}$ & $\begin{array}{c}16.93 \pm 2.44 \\
17.11 \pm 2.66\end{array}$ & $-0.178 \pm 0.371$ & 0.631 \\
\hline $\mathrm{IMD}^{13}$ & $\begin{array}{l}\text { Female } \\
\text { Male }\end{array}$ & $\begin{array}{l}98.42 \pm 4.39 \\
107.52 \pm 4.65\end{array}$ & $-9.096 \pm 0.658$ & $<0.001$ \\
\hline IMSLD $^{14}$ & $\begin{array}{l}\text { Female } \\
\text { Male }\end{array}$ & $\begin{array}{c}117.49 \pm 5 \\
126.82 \pm 3.86\end{array}$ & $-9.327 \pm 0.661$ & $<0.001$ \\
\hline MMCA $^{15}$ & $\begin{array}{c}\text { Female } \\
\text { Male }\end{array}$ & $\begin{array}{c}68.19 \pm 9.82 \\
69.57 \pm 10.06\end{array}$ & $-1.377 \pm 1.448$ & 0.343 \\
\hline \multicolumn{5}{|c|}{$\begin{array}{l}{ }^{1} \text { The distance between the porion and the right mastoidale } \\
2 \text { The distance between the porion and the left mastoidale } \\
{ }^{3} \text { Right mastoid length } \\
{ }^{4} \text { Left mastoid length } \\
5 \text { The distance between the mastoidale and the right mastoid incision } \\
{ }^{6} \text { The distance between the mastoidale and the left mastoid incision } \\
{ }^{7} \text { Right mastoid height } \\
8 \text { Left mastoid height } \\
{ }^{9} \text { Right mastoid width } \\
10 \text { Left mastoid width } \\
11 \text { The distance between the lower point of the mastoid triangle and the } \\
\text { most prominent convex surface of the right mastoid } \\
{ }^{12} \text { The distance between the lower point of the mastoid triangle and the } \\
\text { most prominent convex surface of the left mastoid } \\
{ }^{13} \text { Intermastoidale distance } \\
{ }^{14} \text { The distance between the most prominent convex surface points of } \\
\text { the right and left mastoid triangles } \\
15 \text { The angle between two lines drawn from the most prominent right and } \\
\text { left mastoid points }\end{array}$} \\
\hline
\end{tabular}

Table 2 shows the correlation matrix between the independent variables for all samples. The highest positive correlation was observed between M-I.R and M-H.R and the highest negative correlation was observed between IMD and MMCA.

Table 2 - Correlation matrix between independent right-side variables for all cases.

\begin{tabular}{|lccccccccc} 
& P-M.R & M-L.R & M-I.R & M-H.R & M-W.R & M-FR & IMD & IMSLD & MMCA \\
\hline P-M.R & 1.00 & 0.543 & 0.204 & 0.505 & -0.010 & -0.026 & 0.093 & 0.192 & 0.149 \\
\hline MLR & & 1.00 & 0.458 & 0.373 & -0.013 & -0.200 & 0.134 & 0.032 & 0.003 \\
\hline M-I.R & & & 1.00 & 0.844 & 0.200 & 0.109 & 0.012 & 0.132 & 0.026 \\
\hline MH.R & & & 1.00 & 0.165 & 0.151 & 0.016 & 0.237 & 0.137 \\
\hline MW.R & & & & 1.00 & 0.510 & -0.033 & 0.125 & -0.248 \\
\hline MF.R & & & & & 1.00 & -0.073 & 0.380 & -0.176 \\
\hline IMD & & & & & & 1.00 & 0.715 & -0.285 \\
\hline IMSLD & & & & & & & 1.00 & 0.054 \\
\hline MMCA & & & & & & & & 1.00 \\
\hline
\end{tabular}

The discriminant model developed for sex determination based on the right side variables will be as follows.

$$
\begin{array}{lrr}
\text { DF }=0.191 & \text { PM.R }+0.083 & \text { ML. } R+.006 \\
\text { MI.R }+0.434 & \text { MH.R-0.381 } & \text { MW.R+0.188 } \\
\text { MF.R+0.604 IMD+0.118 IMSLD+0.065 MMCA }
\end{array}
$$

Table 3 shows the correlation between each independent variable with the discriminant function. These values are equivalent to factor loadings in factor analysis. The closer these numbers are to one indicates the more effective role that variable has in the discriminant function. The results show that for the right-sided discriminant model IMSLD and IMD played the most roles in sex segregation. The cut-off score for discrimination between the gender is $1 / 2$ $(-1.279+1.579)=0.3$ if the number obtained from DF function is greater than 0.3 the subject is classified as female and if the DF is less than 0.3 , the case is classified as male.

Table 3 - The correlation between each independent variable and the discriminant function model. 
Table 4 shows the success rate of the discriminant function in the correct classification of observations. In this table, there are two methods of Original and Crossvalidated for the classification process and each has its performance in its own right. However, the second method is usually more accurate. This method is based on the assumption that we should not take the observation we intend to predict as part of the classification process. Thus in this method, each observation at each stage is classified according to a function that is constructed from observations other than the observation itself. According to the table, it can be seen that the discriminant model based on the right variables with $93.7 \%$ accuracy was able to distinguish the two sexes. Also based on the validation set, the model of discriminant based on the right variables with $92.6 \%$ accuracy was able to distinguish the two sexes.

Table 4 - Predictive performance of linear discriminant model in terms of the right variables.

\begin{tabular}{ccccc}
\multicolumn{4}{c}{ Predicted Sex } \\
& & Female & Male & Total \\
& & N(\%) & N(\%) & N(\%) \\
\hline \multirow{2}{*}{ Original } & Female & $97(92.4)$ & $8(7.6)$ & $105(100)$ \\
& Male & $4(4.7)$ & $81(95.3)$ & $85(100)$ \\
Cross- & Female & $96(91.4)$ & $9(8.6)$ & $105(100)$ \\
valiated & Male & $5(5.9)$ & $80(94.1)$ & $85(100)$ \\
\hline
\end{tabular}

\section{DISCUSSION}

Sex identification plays an important role in identifying individuals. If the skeleton is fully present, sex determination is successful. But in accidents and fires where there are only fragments of the skeleton, single bones are used to determine sex. Sex is best determined by pelvic examination, but often the pelvis is damaged or unavailable. Skulls are of secondary importance in determining sex; of course, sex determination by the skull is reliable only after puberty is complete [22].

From skull bones, there is general agreement among researchers about the role of the mastoid process in sex determination and sex determination by the mastoid triangle is possible both morphologically and morphometrically. The morphometric method is more preferable to the morphological method because of its objectivity and providing statistical data [23].

In most previous studies, mastoid triangle measurements were performed on dry skulls using a Caliper, but in the present study, measurements were made on 3D images from CBCT data by linear and angular measurement software tools and this has led to greater accuracy in measurements.

In the present study, various parameters on mastoid (MW, MF, MI, ML, and PM) and inter-mastoid parameters (MMCA, IMSLD, and IMD) were measured and evaluated. In the present study except MF and MMCA significant differences were found for the mean of all variables between the two sexes. No significant difference between the two sexes for the angle variable between the two mastoids suggests that although the angle is slightly higher in males than in females, the angle between the two mastoids is more reflective of mastoid pattern and shape and less affected by sex [9].

Amin et al. [1] measured parameters similar to the present study of mastoid proliferation in the Jordanians population and significant differences were found between male and female in all measured variables. Also, Saini et al. [23] in a study of North Indian population performed 8 different measurements on the mastoid triangle and significant differences were found between males and females in all measured distances. In the study of Sujarittham et al. [24] and Bhayya et al. [16] mastoid length and width between men and women were significant.

In the study of Galdames et al. [25] on the Brazilian population, there was only a significant difference between the size of the mastoidale porion between the male and female. These differences are due to differences in the 
studied population as well as differences in the measurement of variables in different studies. In the present study, the measured values for all variables except MW were higher for men than for women. The greater the measured value for males could be due to the longer growth period than females and the larger muscle size in males [17]. In the case of MW or mastoid width, it appears that the mastoid bone in females is rounder than that in males; its value is higher in women than in men. Consistent with the present study in the study of Amin et al. [1] all variables except MW, MMCA, and MF were higher in men than women [1]. Also in the study of Kanchan et al. [9] Gupta et al, [18] and Galdames et al. [25] all measurements were more in men than women. The results of the present study showed that for the measured mastoid variables in this study there was no significant difference between right and left. Consistent with the present study in the study of Ibrahim et al. [21] and Amin et al. [1] and Madadin et al. [15] there was no significant difference in the dimensions of the two sides. But in the study of Kamkes et al. [19] there was asymmetry in the Portuguese population between right and left. Also in a study of Paiva et al. [26] done on dry skull xerographic copies, there was a significant difference between right and left.

In the present study, a discriminant model was developed based on the measured variables that were able to discriminate sex with $93.7 \%$ overall accuracy. In the study of Amin et al. [1] the accuracy of the obtained discriminant model was $90.6 \%$, in the study of Ibrahim et al. [21] the accuracy of $84.4 \%$, and in the study of Gupta et al., [18] 90\%, and in the study of Saini et al., [22] 87\% accuracy, in Sumati et al. [16] accuracy $76.7 \%$ and Bhayya et al. [16] accuracy $82 \%$ and Sujarittham et al. [24] accuracy 78\% were obtained.

In contrast, in some previous studies, the accuracy of the discriminant model obtained for sex differentiation was low, such as that of Kemkes et al. [19] and Singh et al., [25] who achieved $65 \%$ and $61 \%$ accuracy, respectively. Also in the study of Galdames et al. [27] the overall accuracy was $64.2 \%$ which was high sensitivity (93\%) for men and low sensitivity (17.7\%) for women.

Differences in the accuracy of the discriminant model obtained in different studies emphasize the existence of differences in the skulls of individuals in different populations that are affected by the environment and nutrition. In addition, the position of the skull landmarks varies slightly between populations. Also, the difference in the accuracy of the obtained discriminant model can be due to differences in the methodology of different studies. In the present study, using all variables, an equation for sex determination was obtained that in this equation IMD and IMSLD had the highest correlation and thus had the most effect on sex determination, which is in line with the study of Amin et al. that IMD, had the most impact on their study. Other studies have not examined the role of IMD in sex determination. But among the variables studied in other studies, Gupt et al. [18] found the greatest effect for the mastoid length variable and the least effect for the mastoid width. In the study of Passey et al. [28] and Patniak et al. [29] mastoid length had the most influence on sex determination. In Saini et al. [23] the greatest effect was related to the AstMS variable, the distance between the asterion and mastoid. In the present study, mastoid length and width were moderately correlated with sex determination.

In the present study and in our study population, if the number obtained from the discriminant model (DF) is greater than 0.3 , it can be estimated that the sex of the person is male, and if less than 0.3 it can be estimated that a person's sex is female. In the study of Amin et al conducted on the Jordanian population, if the model had a score above zero, the sex of the person was male and if it was less than zero, it could be estimated that the sex was female [1].

Also in the Ibrahim study in the Malaysian 
population, the number obtained is -0.199 that if the number obtained from DF is greater than this number the sex is male and if it is less than that number it is estimated that the female [21].

In most previous studies, the asterion (the lambdoid, occipito-mastoid, and parieto-mastoid fissure junction) was measured as a vertex of the measured mastoid triangle, but the study uses a mastoid incision that is both sharper and lower than the asterion, instead of asterion. Amin et al., Sujarittham et al. also consider the mastoid incision in their studies [1, 24]. The discriminant model obtained in the present study was able to accurately differentiate sex by measuring the dimensions of the mastoid triangle; this is due to the study of all the parameters of the mastoid variable (PM, ML, MI, MW, MF) and the variable parameters between the two mastoids (IMD, IMSLD, and MMCA) together.

In addition, the results obtained by researchers for different populations shows that discriminant analysis of each population is the best sex determinant for the same population and racial differences in different parts of the world can affect the dimensions of the mastoid bone and therefore the accuracy of the model obtained [25,30].

This can be clearly seen in the study of Kemkes et al. [19] conducted on two different populations, German and Portuguese, and presented different results for the discriminant analysis of these two populations.

Finally, it should be noted that sex determination using a mastoid process has some limitations, for example, the results of the study on a particular population cannot be generalized to other population. It can be possible to determine the sex of the person whose identity is unknown using discriminant analysis model only if we are aware of the nationality and race of the individual. For this reason, it is recommended to conduct a study on a larger statistical population in which age, race, and other factors can be taken into account.

\section{CONCLUSION}

The results of this study showed that measuring the dimensions of the mastoid triangle is a very good method for sex determination. In the population studied in the present study, significant results were found for most of the variables of the mastoid triangle observed by sex. Using these variables, a discriminant model was developed that had an accuracy greater than $90 \%$ for sex segregation. In this model, intermastoidale distance (IMD) the lateral surfaces of the left and right mastoids (IMLSD) had the highest correlation and effect on sex determination. The model of sex-specific discriminant analysis using dimensions of a mastoid triangle is highly population-dependent because environmental, genetic, nutritional, and migration factors can affect mastoid bone shape and size.

\section{Acknowledgments}

The authors are grateful to Vice Chancellor of Research, Hamadan University of Medical Sciences for their support (Grant number: 9710186171).

\section{Funding}

This study was partially supported by Dental Research Center, Vice Chancellor of Research, Hamadan University of Medical Sciences. (Grant number: 9710186171)

\section{Conflict of interest}

The authors have no proprietary, financial, or other personal interest of any nature or kind in any product, service, and/or company that is presented in this article.

\section{Regulatory Statement}

This study was conducted in accordance with all the provisions of the local human subjects oversight committee guidelines and policies of: Ethics Committee of Hamadan University of Medical Sciences. The approval code for this study is: IR.UMSHA.REC.1397.715. 


\section{REFERENCES}

1. Amin W SM-W, Othman D, ThunaibatH. Osteometric assessment of the mastoid for sex determination in Jordanians by discrimination function analysis. Am J Med Biol. 2015;3(4):117-23.

2. Cattaneo C. Forensic anthropology: developments of a classical discipline in the new millennium. Forensic Sci Int. 2007;165(2-3):185-93.

3. Krishan K, Kanchan T,Passi N, DiMaggio JA. Heel-ball (HB) index: sexual dimorphism of a new index from foot dimensions. J Forensic Nurs. 2012;57(1):172-5

4. Balci Y, Yavuz M, Cağdir S. Predictive accuracy of sexing the mandible by ramus flexure. Homo. 2005;55(3):229-37.

5. Robinson MS, Bidmos MA. An assessment of the accuracy of discriminant function equations for sex determination of the femur and tibia from a South African population. Forensic Sci Int. 2011;206:212.e1e5.

6. Gonzalez RA. Determination of sex from juvenile crania by means of discriminant function analysis. J Forensic Sci. 2012;57:24e34.

7. BiwasakaH,Aoki Y,Sato K, Tanijiji T,Fujita S, Dewa K, et al. Analyses of sexual dimorphism of reconstructed pelvic computed tomography images of contemporary Japanese using curvature of the greater sciatic notch, pubic arch and greater pelvis. Forensic Sci Int. 2012;219:288.e1e8.

8. Krogman WM, Iscan YM. The human skeleton in forensic medicine. 2nd ed. Springfield, llinois: Charles C. Thomas Pub; 1986.

9. Kanchan T, Gupta A, Krishan K. Estimation of sex from mastoid triangle-A craniometric analysis. JForensic Leg Med. 2013;20(7):855-60.

10. Macaluso PJ Jr. Investigation on the utility of permanent maxillary molar cusp areas for sex estimation. Forensic Sci Med Pathol. 2011Sep;7(3):233-47. doi: 10.1007/s12024-010-9204-7

11. Schiwy-BochatKH. The roughness of the supranasal region--a morphological sex trait Forensic Sci Int. 2001Mar 1;17(1-2):7-13. doi: 10.1016/s03790738(00)00434-5 May H, Peled N, Dar G, Cohen H, Abbas J, Medlej B, etal. Hyperostosis frontalis interna: criteria for sexing and aging a skeleton. Int $J$ Legal Med. 2011Sep;125(5):669-73. doi: 10.1007/s00414-010-0497-6. Epub 2010 Jul 23.PMID:20652712

12. WescottDJ,Moore-Jansen PH. Metric variation in the human occipital bone: forensic anthropological applications. J Forensic Sci. 2001Sep;46(5):1159-63.

13. Uthman AT,Al-Rawi NH, Al-Timimi JF.Evaluation of foramen magnum in gender determination using helical CT scanning. Dentomaxillofac Radiol. 2012 Mar;41(3):197-202. doi: 10.1259/dmfr/21276789

14. Madadin M, Menezes RG, AI Dhafeeri O, Kharoshah MA,Al lbrahim R, Nagesh $\mathrm{K}$, et al. Evaluation of the mastoid triangle for determining sexual dimorphism: A Saudi population based study. Forensic Sci Int. 2015 Sep;254:244.e1-4. doi: 10.1016/j.forsciint.2015.06.019
15. Bhayya H, Tejasvi MA, Jayalakshmi B, Reddy MM. Craniometric assessment of sex using mastoid process. J Indian Academy Oral Med Radiol. 2018;30(1):52.

16. Scheuer L. Application of osteology to forensic medicine. Clin Anat. 2002 Jun;15(4):297-312. doi:10.1002/ca.10028

17. Gupta AD, Banerjee A, Kumar A, Rao SR, Jose J.Discriminant function analysis of mastoid measurements in sex determination. JLife Sci. 2012;4(1):1-5.

18. Kemkes A, Göbel T.Metric assessment of the "mastoid triangle" for sex determination: a validation study. J Forensic Sci. 2006 Sep;51(5):985-9. doi: 10.1111/j.1556-4029.2006.00232.x

19. Koh KK, Tan JS, Nambiar P, Ibrahim N, Mutalik S, Khan Asif M. Age estimation from structural changes of teeth and buccal alveolar bone level.J Forensic Leg Med. 2017 May;48:15-21. doi: 10.1016/j.jflm.2017.03.004

20. Ibrahim A, Alias A, Shafie MS, Das S, Nor FM. Osteometric estimation of sex from mastoid triangle in malaysian population. Asian JPharm Clin. 2018;11(7):303-7.

21. Sumati, Patnaik VVG, Phatak A. Determination of sex by mastoid process by discriminant functions analysis. J Anat Soc India. 2010;59:222e8.

22. Saini V, Srivastava R, Rai RK, Shamal SN, Singh TB, Tripathi SK. Sex estimation from the mastoid process among North Indians. J Forensic Sci. 2012 Mar;57(2):434-9. doi: 10.1111/j.1556-4029.2011.01966.x

23. Sujarittham S, VichairatK, Prasitwattanaseree S, MahakkanukrauhP.Thai human skeleton sex identification by mastoid process measurement. Chiang Mai Med J. 2011;50(2):43-50.

24. Galdames ICS, Matamala DAZ, Smith RL. Sex determination using mastoid process measurements in Brazilian skulls. Int J Morphol. 2008;26(4):941-4.

25. Paiva LAS, Segre M. Sexing the human skull through the mastoid process. Rev Hosp Clin Fac Med Sao Paulo. 2003;58:15e20.

26. Singh RP, Verma SK, Tyagi AK. Determination of sex by measurement of area of mastoid triangle in human skull. Indian Internet J Forensic Med Toxicol. 2008;6:29e43.

27. Passey J, Mishra SR, Singh R, Sushobhna K, Singh S, Sinha P.Sex determination using mastoid process. Asian J Med Sci. 2015;6(6):93-5.

28. Patnaik $\mathrm{V}$, PhatakA. Determination of sex from mastoid process by discriminant function analysis. J Anat Society India. 2010;59(2):222-8.

29. Nagaoka T, Shizushima A, Sawada J, Tomo S, Hoshino K, Sato H, etal. Sex determination using mastoid process measurements: standards for Japanese human skeletons of the medieval and early modern periods. Anthropol Sci. 2008;116(2):105-13.

\section{Dr Maryam Farhadian}

\section{(Corresponding address)}

Department of Biostatistics, School of Public Health and Research Center for Health Sciences, Hamadan University of Medical Sciences, Hamadan, Iran.

Date submitted: 2019 Mar 4

Accept submission: 2020 May 20 